\title{
Tirtha Campuhan: Karya Komposisi Baru dengan Media Gamelan Semar Pagulingan
}

\author{
Putu Paristha Prakasih, I Gede Yudarta, dan Hendra Santosa ${ }^{1}$ \\ Jurusan Seni Karawitan, Fakultas Seni Pertunjukan ISI Denpasar
}

\begin{abstract}
Tirtha Campuhan: A New Composition Work by Using Semar Pagulingan Gamelan as Media. In Karawitan, the process of creating works of art is essential to produce a renewal of tradition so that the process of creating these works of art can be said to be musical creation. For creating the musical creation, the author was inspired by the uniqueness of the holy place in Pata Sari Kuta precisely in Tirtha Campuhan Temple, which was used as the idea of creation. The uniqueness in Tirtha Campuhan Temple is a natural phenomenon of river flow in which there is a mixture of two river streams with seawater to form a new river called Campuhan river. As the name implies, Tirtha Campuhan Temple has a mixture of river flow from dead river mouths (tukad mati, tukad ening) and rivers in Badung, so that the river flow in the temple forms a new river flow (tukad pateluan, tukad mati, and tukad ening). The local community often uses the river water in the temple as tirtha for pengelukatan or cleaning and also used as medicine. From this information, the authors found the idea of making Tirtha Campuhan as a source of inspiration. The author realized the idea of creation in the form of the creation of musical compositions using the media revealed Semar Pagulingan. In this media, Semar Pagulingan applied tirtha and campuhan or mixture in making the tirtha by combining several patets in the Semar Pagulingan gamelan. The purpose of creating this creative music is to build a harmonious atmosphere in the preparation of melodies using patet mixing.
\end{abstract}

Keywords: tirtha campuhan; semar pagulingan; creation music

\begin{abstract}
ABSTRAK
Dalam seni karawitan, proses penciptaan karya seni merupakan hal penting untuk menghasilkan sebuah pembaharuan terhadap tradisi sehingga proses penciptaan karya seni tersebut dapat dikatakan sebagai musik kreasi. Dalam upaya menciptakan sebuah musik kreasi, penulis mendapat inspirasi dari keunikan tempat suci di Pata Sari Kuta tepatnya di Pura Tirtha Campuhan yang dijadikan sebagai ide penciptaan. Keunikan yang ada di Pura Tirtha Campuhan merupakan fenomena alam aliran sungai yang didalamnya terdapat campuran dua aliran sungai dengan air laut sehingga terbentuk sungai baru yang bernama sungai campuhan. Sesuai dengan namanya, Pura Tirtha Campuhan memiliki campuran aliran sungai dari muara sungai mati (tukad mati, tukad ening) dan sungai yang berada di Badung, sehingga aliran sungai di Pura tersebut membentuk sebuah aliran sungai baru (peteluan tukad, tukad mati, tukad ening). Air sungai yang ada di Pura tersebut sering dimanfaatkan oleh masyarakat setempat sebagai tirtha untuk pengelukatan atau pembersihan dan juga digunakan sebagai obat. Dari keterangan tersebut, maka penulis menemukan ide menjadikan Tirtha Campuhan sebagai sumber insiprasi. Penulis merealisasikan ide penciptaan tersebut dalam bentuk garapan komposisi musik kreasi dengan menggunakan media ungkap Semar Pagulingan. Dalam media ungkap Semar Pagulingan penata mengaplikasikan tirtha dan campuhan atau campuran dalam membuat tirtha tersebut dengan menggabungkan beberapa patet dalam gamelan Semar Pagulingan. Tujuan penciptaan musik kreasi ini adalah untuk membangun suasana harmonis dalam olahan melodi menggunakan pencampuran patet.
\end{abstract}

Kata kunci: tirtha campuhan; semar pagulingan; musik kreasi

Alamat korespondensi: Jurusan Seni Karawitan, Fakultas Seni Pertunjukan ISI Denpasar, Jalan Nusa Indah Denpasar Bali. Tlp.: (0361) 227316. E-mail: hendrasnts@gmail.com. 


\section{Pendahuluan}

Pura Tirtha Campuhan terletak di muara tukad mati yang berdekatan dengan hutan mangrove, di Jalan Bypass Ngurah Rai Gang Pata Sari 1. Pura Tirtha Campuhan merupakan pura yang disungsung (diampu) oleh keluarga besar Jro Mangku Sukra Pata Sari Kuta. Pura Tirtha Campuhan dibangun pada tahun 2008 dan di diplaspas pada tanggal 9 September 2009 yang dipuput oleh Jero Mangku A. A. Kompyang Punia (mangku Pura Desa Adat Kuta). Puncak upacara odalan di Pura Tirtha Campuhan adalah pada hari Budha Kliwon Gumbreg menurut perhitungan Kalender Bali.

Fenomena yang terjadi di Pura Tirtha Campuhan memiliki keunikan yaitu terdapat dua aliran sungai dari arah utara, timur dan aliran air laut dari arah selatan. Aliran air dari utara berasal dari sungai mati (Tukad mati, Tukad mengening), sedangkan dari arah timur berasal dari sungai Badung, dan pada air laut dari selatan berasal dari laut Teluk Benoa. Aliran-aliran tersebut bermuara dan bercampur di tengah-tengah sungai.

Sesuai dengan wawancara yang dilakukan penulis dengan Jro Mangku Sukra dijelaskan bahwa secara niskala (yang tidak bisa dilihat oleh mata) tiga aliran air sungai dan laut tersebut memiliki arti tersendiri, seperti dalam aliran sungai dari utara merupakan pemargi atau jalan dari Ratu Niang, pada aliran sungai dari arah timur merupakan pemargi atau jalan dari Ratu Gede Dalem Ped, dan pada aliran air laut dari selatah pemargi atau jalan dari Ratu Lingsir, dari campuran tersebut terbentuklah pusaran air yang menyerupai sumur. Sumur tersebut dinamai sumur pusering jagat dengan lingih Ida Tri Sakti (wawancara dengan Jro Mangku Sukra, 17 Januari 2018).

Musik kreasi merupakan bentuk-bentuk musik yang diciptakan dari rekayasa baru terhadap bentuk-bentuk musik tradisional (Sugiartha, 2008). Hal ini juga dikuatkan oleh pendapat bahwa munculnya musik karya baru komposisi karawitan yang inovatif berasal dari pemaknaan baru terhadap seni karawitan tradisi (Suneko, 2016). Musik kreasi yang dibuat penulis bersifat bebas atau berkarya tanpa batas sesuai dengan ide atau konsep para penggarap, yang direalisasikan dengan media ungkap dengan menggunakan gamelan Semar Pagulingan. Kreativitas dalam musikalitas pada penciptaan musik kreasi baru dapat ditelusuri melalui pembongkaran-pembongkaran pada konsep struktur, melodi, ritme, dinamika, dan harmoni yang memiliki implikasi pada perubahan ekspresi musikal (Sugiartha, 2012).

Ide penciptaan dalam sebuah karya musik biasanya berasal dari gagasan yang terinspirasi dari beragam realitas kehidupan sehari-hari seperti keluarga, lingkungan, fenomena alam, bencana, sosial, budaya, politik, dan lainnya (Warsana, 2012). Melalui konsep tentang ide penciptaan seni, maka penulis menjadikan suasana campuran air yang berada di Pura Tirtha Campuhan sebagai ide penciptaan. Komposisi ini menggunakan media ungkap gamelan Semar Pagulingan. Dalam tradisi Bali, gamelan Semar Pagulingan dipakai untuk mengiringi raja-raja sewaktu di peraduan dan mengiringi tari Legong dan Gandrung yang semula dilakukan oleh abdi-abdi raja (Bandem, 1995). Gamelan Semar Pagulingan saih pitu diperkirakan muncul pada abad ke XIV, semenjak kelahirannya, gamelan Semar Pagulingan saih pitu merupakan salah satu gamelan penting yang ikut memperkaya khasanah karawitan Bali (Rai, 1998).

Gamelan Semar Pagulingan merupakan Gamelan yang berlaras pelog dengan tujuh nada (Santosa, 2019). Tujuh nada suara dalam gamelan Semar Pagulingan terdapat nilai estetis jika dengan pengider buana dan konsep estetika keseimbangan hidup. Tujuh bunyi yang terdapat dalam genta pinara pitu oleh Granoka dipandang sebagai konsepsi puncak nada-nada asli (yang bersifat keTuhanan), suci murni, indah, dan yang selalu menghantarkan sukma hati dalam pribadi sang hamba (Donder, 2005). Dengan pandangan Granoka tersebut penulis merasa tertarik untuk membuat suatu tabuh kreasi baru yang bertemakan religi dengan judul Tirtha Campuhan. Dalam media ungkap Semar Pagulingan penulis menginterpretasikan tirtha dan campuhan atau campuran dalam membuat tirta tersebut dengan menggabungkan beberapa patet dalam gamelan Semar Pagulingan. Dengan menggunakan gamelan Semar Pagulingan mempermudah penulis dalam mengaplikasikan sebuah fenomena 
campuran aliran air sungai dengan menggunakan patet, serta menginterpretasikan suasana air dan aliran air sungai yang bercampur.

Pertemuan aliran air sungai merupakan sumber ide utama dari penggarapan karya seni karawitan Tirtha Campuhan. Penulis ingin mengangkat sifat air yang hening (tukad mati), air sungai yang bercampur, dan air sungai yang sudah mengalami pencampuran, yang akan diaplikasikan dengan patet atau patutan dalam barungan gamelan Semar Pagulingan. Beberapa patet atau patutan yang ada dalam barungan gamelan Semar Pagulingan akan dicampur menjadi satu kesatuan yang harmoni untuk mengisi dalam setiap bagiannya.

Secara konsep garapan, komposisi Tirtha Campuhan merupakan garapan kreasi baru, hal ini dapat dilihat dari wujud garapannya. Wujud adalah sesuatu hal yang dapat dilihat dan dapat didengar. Wujud dapat secara nyata dipersepsikan melalui mata dan telinga. Dalam hal ini wujud dapat dilihat dari bentuk dan struktur sebuah karya seni (Djelantik, 1990). Wujud garapan Tirtha Campuhan merupakan garapan kreasi yang menggunakan media ungkap Semar Pagulingan.

Setiap kegiatan yang dilakukan pastinya mempunyai tujuan yang jelas. Tujuan garapan karya seni yang ditata dengan unsur-unsur musik akan memiliki tujuan yang jelas. Adapun tujuan dari karya seni Tirtha Campuhan yaitu menciptakan sebuah garapan tabuh kreasi dengan media Semar Pagulingan yang kreatif dan diharapkan mampu meningkatkan apresiasi masyarakat terhadap tabuh kreasi dalam media ungkap Semar Pagulingan. Untuk mencoba mengaplikasikan konsep campuran (campuhan) aliran sungai ke dalam media ungkap gamelan Semar Pagulingan dengan mencampur beberapa patet atau patutan dalam olahan musikalnya.

Tujuan penulisan ini untuk mendeskripsikan proses penggarapan komposisi tabuh kreasi Tirtha Campuhan. Pada penggarapan komposisi ini, terdapat proses pemilihan patet-patet yang akan diaplikasikan dengan olahan ritme dan tempo hingga menjadi bahasa musikal yang harmonis dalam setiap bagiannya.

Selain mendeskripsikan proses penggarapan komposisi tabuh kreasi Tirtha Campuhan, tulisan ini juga akan mendeskripsikan bentuk dan struktur komposisi Tirtha Campuhan. Tirtha Campuhan merupakan komposisi tabuh kreasi yang menggunakan media ungkap Semar Pagulingan saih pitu. Komposisi ini terdiri dari 5 bagian, yaitu pangawit, gagenderan, pangawak, pangecet, dan penyuud.

Pada bagian pertama tabuh kreasi Tirtha Campuhan terdapat melodi yang lembut dan dipadukan dengan tempo lambat dan menggunakan satu patet. Bagian pertama menggambarkan suasana yang ada di tukad ening. Bagian kedua, menggunakan tempo yang lebih cepat dari bagian pertama dengan menggunakan melodi yang sama seperti pada bagian pertama. Bagian ketiga, olahan melodi menggunakan campuran tiga patet yaitu patet selisir, patet baro, dan patet tembung dengan tempo lambat. Bagian keempat, melodinya menggunakan campuran tiga patet seperti pada bagian tiga dengan menggunakan tempo sedang. Sedangkan pada bagian kelima, menggunakan melodi yang sama seperti pada bagian keempat dengan tempo lebih lambat dari bagian pertama, dan menggunakan vokal.

Hasil dari garapan karawitan Tirtha Campuhan ini diharapkan dapat memberikan manfaat yang positif, seperti: menambah wawasan, menambah perbendaharaan karya musik kreasi dengan menggunakan gamelan Semar Pagulingan, menjadi sumber salah satu acuan karya karawitan bagian kalangan akademisi karawitan, serta sebagai upaya melestarikan sekaligus mengembangkan potensi seni tradisi dengan menggunakan gamelan Semar Pagulingan dalam konteks baru (kreasi).

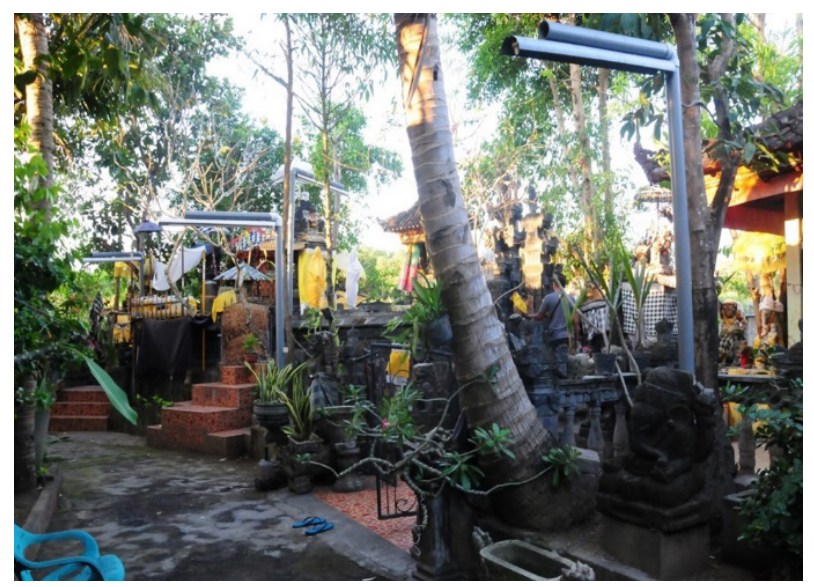

Gambar 1. Pura Tirtha Campuhan. (Sumber: Paristha, 2018) 


\section{Proses Penciptaan}

Proses penciptaan merupakan dasar dari sebuah pementasan karya komposisi musik, sehingga dibutuhkan tahapan eksplorasi dan eksperimentasi (Slamet \& Djohan, 2017). Penggarap komposisi harus menentukan beberapa konsep garapan yang akan digunakan sebagai acuan maupun sebagai dasar dalam manciptakan suatu karya seni khususnya seni karawitan yang mampu diterima dikalangan masyarakat luas.

Kreativitas merupakan unsur penting dalam membuat komposisi karya seni yang diibaratkan sebuah jantung dalam proses penggarapan karya seni tersebut. Seseorang diberikan sebuah kemampuan khusus untuk mencipta, maka seseorang dapat memasukan atau mendapatkan sebuah ide, simbol, dan objek yang menjadi inspirasinya ke dalam garapannya. Dalam setiap penciptaan karya seni karawitan, penata akan memasukan ide-ide ke dalam karyanya melalui proses kreativitas. Proses penciptaan karya seni Tirtha Campuhan, penata berpedoman memakai tiga tahapan yang diambil dari konsep Alma M. Hawkins dalam buku Creating Trough Dance, yang dialih bahasakan oleh Y. Sumandiyo Hadi ISI Yogyakarta (Hawkins, 1990). Dalam buku tersebut ada tiga tahapan dalam proses penggarapan karya seni antara lain: tahap penjajagan (exsploration), tahap percobaan (improvisation), dan tahap pembentukan (forming) (Agus et al., 2018: 99; Hadi, 1990). Ketiga tahapan ini digunakan dalam penataan komposisi karawitan Semar Pagulingan kreasi Tirtha Campuhan.

Berikut adalah penjabaran ketiga tahapan yang digunakan pada penataan komposisi karawitan Tirtha Campuhan:

a. Tahap pertama adalah penjajagan (exploration). Tahap ini merupakan tahap pencarian ide atau gagasan (Diaristha, Sutirtha, \& Widnyana, 2018). Dalam mewujudkan sebuah garapan, penulis menemukan sebuah ide dari fenomena yang terjadi di Pura Tirtha Campuhan khususnya pada tiga aliran air sungai yang menarik untuk diangkat dan dijadikan sebuah konsep. Setelah mendapatkan ide maupun konsep yang tepat, penata memakai nama Pura Tirtha Campuhan sebagai judul dari sebuah garapan musik kreasi dengan judul Tirtha Campuhan. Pada tahap exsplorasi penata mulai memikirkan unsurunsur musik seperti nada-nada, ritme, melodi, dinamika dan tempo yang akan dituangkan pada gamelan Semar Pagulingan. Pada tahap improvisasi penata lebih dahulu memikirkan cara untuk menggabungkan nada-nada dan melodi agar menjadi kesatuan yang selaras, karena menggabungkan patet dalam barungan Semar Pagulingan merupakan hal yang tidak mudah, jika salah menggabungkan maka nada dan melodi akan terkesan janggal. Penulis mulai mencatat notasi-notasi gamelan yang akan dituangkan ke dalam gamelan Semar Pagulingan. Pada tahap eksplorasi terjadi juga proses aksi-reaksi dan stimulus antara pemusik dan penggarap (Susanti, 2015).

b. Tahap percobaan (improvisasi). Dalam tahap ini, penata mulai menggabungkan ide, dan konsep ke dalam bentuk maupun struktur musikal sehingga terwujud sebuah garapan kreasi baru. Tahapan ini menjadi sangat penting dalam memilih, mempertimbangkan, membedakan dan memadukan pola melodi, pada ritmeritme dengan tempo dan dinamika tertentu agar menjadi selaras dan memiliki nilai estetis. Dalam penataan bentuk, seorang seniman pasti memiliki rasa tidak puas, hal ini menunjukkan seorang seniman merupakan individu yang kreatif. Proses kreatif pada kompoisisi ini dimulai dengan mencari ide-ide yang ada dilingkungan sekitar Pura Tirtha Campuhan, sehingga dapat dilakukan pembenahan. Proses

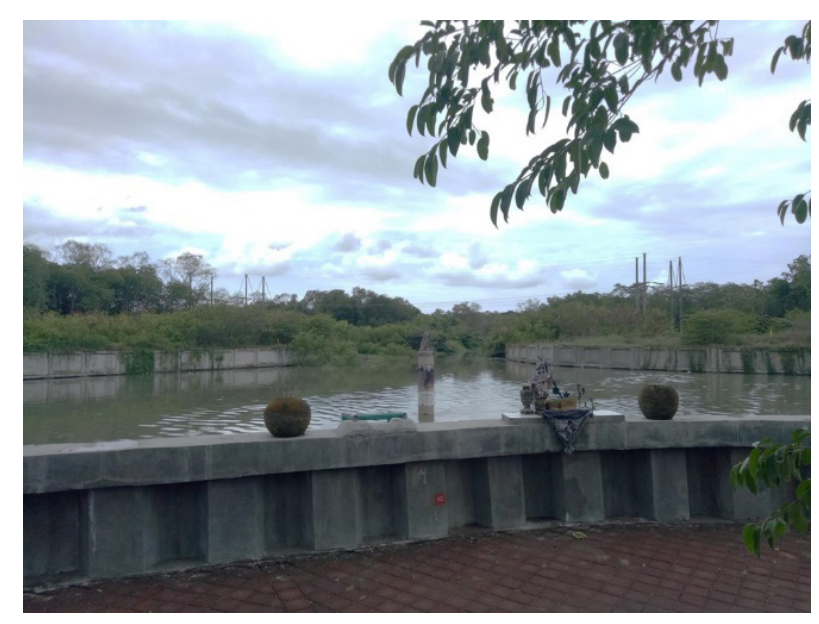

Gambar 2. Tempat bertemunya dua sumber air. (Sumber: Paristha, 2018) 
pembenahan ini dilakukan dengan proses penambahan dan pengurangan terhadap rasa musikal yang dianggap kurang sesuai, maka akan terus disempurnakan, sehingga menjadi sebuah garapan baku yang memenuhi rasa estetis.

c. Tahap pembentukan (forming) merupakan tahap terakhir dari sebuah proses penciptaan (Suaida, Novalinda, \& Erman, 2018). Pada tahap ini, penggarap mulai memilih, menghubungkan satu temuan dengan temuan lainnya, baik berupa warna suara, tempo, melodi, dan ritme sehingga bisa menyesesuaikan dengan suasana karakter dalam garapan Tirtha Campuhan. Tahap ini dapat dikatakan sebagai penyempurnaan sebuah garapan, karena dalam merangkai motif-motif patetyang digunakan sering dilakukan percobaan dengan pertimbangan-pertimbangan estetis. Dengan demikian suatu keutuhan komposisi dapat diperhitungkan dengan materi yang sesuai dengan posisi dan kebutuhannya, sehingga bisa disebut dengan pembakuan sebuah garapan. Perbaikan demi perbaikan garapan ini dilakukan dengan harapan garapan akan menjadi lebih rapi dan indah, runut dengan ide dan konsep yang diinginkan. Akhirnya garapan ini bisa berjalan sesuai dengan suasana hati, pikiran, dan imajinasi penata maupun masyarakat pada umumnya.

\section{Tinjauan Pustaka}

Sebagai bentuk pertanggungjawaban sebuah karya seni, maka seniman harus dapat memberikan pertanggungjawaban dengan referensi yang jelas. Setiap pernyataan yang digunakan harus dapat dibuktikan baik secara empiris maupun tertulis, sehingga kajian sumber sangat diperlukan. Kajian sumber dapat berupa sumber pustaka, rekaman audio maupun audio visual, serta data-data informasi secara lisan yang diperoleh dari narasumber. Dari kajian inilah kemudian didapat konsep, ide, gagasan atau teori yang relevan terhadap sebuah karya seni. Bukti-bukti tersebut juga menjadi sumber acuan dalam garapan Tirtha Campuhan. Adapun sumber tertulis yang digunakan dalam garapan ini adalah sebagai berikut: a. Komposisi musik Campuhan yang disusun oleh I Wayan Suarsa pada tahun 2002. Pada komposisi Campuhan dari I Wayan Suarsa ini memiliki judul yang hampir sama pada komposisi Tirtha Campuhan. Pada komposisi Campuhan, ide eksperimen menggunakan laras pelog dan slendro, dan mencari kemungkinan dari teknik permainan melodi dan ritme yang kontras. Perbedaan tersebut terdapat pada instrumen musik yang digunakan yaitu Gong Gede dan Angklung. Komposisi Campuhan memiliki perbedaan dari komposisi Tirtha Campuhan, yaitu pada komposisi Campuhan ide eksperimen berasal dari penggunaan dua laras berbeda yang memiliki penekanan pada kontras antar laras, sedangkan pada komposisi Tirtha Campuhan sumber idenya berasal dari fenomena pencampuran aliran air sungai yang direpresentasikan dengan menggunakan pencampuran patet pada gamelan Semar Pagulingan dan memiliki tema religi.

b. Sumber berikutnya adalah komposisi musik Campuhan karya I Wayan Galung Marwanaya pada tahun 2012. Komposisi ini memiliki judul yang sama dengan komposisi musik karya I Wayan Suarsa yaitu Campuhan. Meskipun memiliki kesamaan judul, namun kedua komposisi musik ini memiliki perbedaan pada ide garapnya. Komposisi musik I Wayan Galung Marwanaya memiliki ide garap fusion atau perpaduan antara elemen musik barat dan gamelan Bali. Ide ini diambil dengan pertimbangan bahwa Campuhan

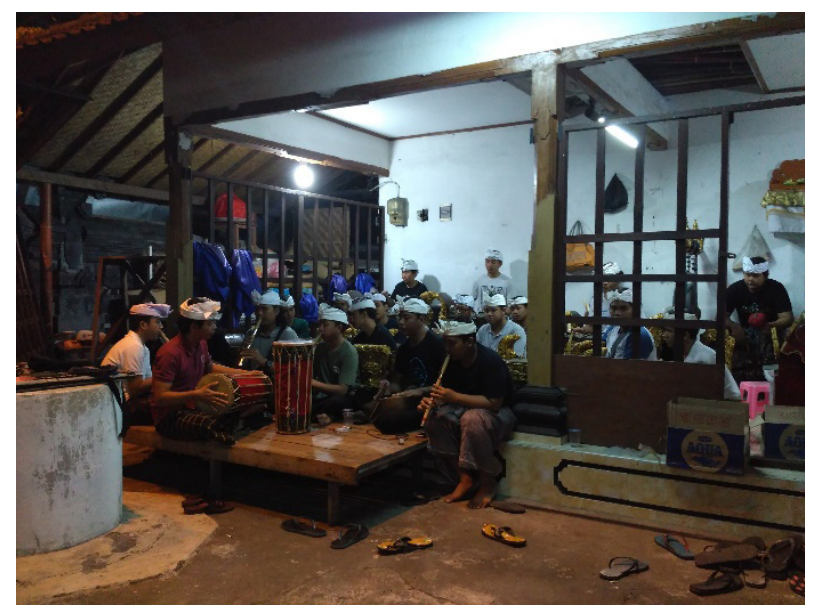

Gambar 3. Proses latihan.

(Sumber: Paristha, 2018) 
merupakan pertemuan dua sungai, dan dalam komposisi ini, Campuhan diartikan sebagai sebuah pencampuran budaya atau musik. Konsep "perpaduan" merupakan konsep yang digunakan I Wayan Galung Marwanaya untuk merealisasikan garapannya. Garapan Campuhan karya I Wayan Galung Marwanaya memiliki kemiripan dengan garapan Tirtha Campuhan. Meskipun memiliki kemiripan dengan komposisi Tirtha Campuhan, namun ide penciptaan dua komposisi tersebut berbeda, pada komposisi Campuhan landasan konsepnya terdapat dua pencampuran sungai, sedangkan pada komposisi Tirtha Campuhan landasan konsepnya terdapat dua pencampuran aliran sungai ditambah satu aliran air laut. Perbedaan lain juga terdapat pada media garapnya, pada komposisi Campuhan karya I wayan Galung Marwanaya menggunakan gamelan Salukat, sedangkan pada komposisi Tirtha Campuhan menggunakan gamelan Semar Pagulingan.

c. Sumber kajian berikut yang digunakan sebagai acuan adalah buku yang ditulis oleh I Wayan Rai dengan judul "Peranan Sruti Dalam Pepatutan Gamelan Semar Pagulingan Saih Pitu” (1998). Buku ini membahas tentang munculnya gamelan Semar Pagulingan. Gamelan Semar Pagulingan Saih Pitu merupakan salah satu bentuk gamelan Bali yang menggunakan laras pelog tujuh nada yang dikenal dengan istilah saih pitu. Gamelan Semar Pagulingan Saih Pitu sudah muncul di Bali sekitar abad ke XIV. Sejak kelahirannya Semar Pagulingan Saih Pitu tetap merupakan salah satu gamelan penting yang ikut memperkaya khasanah karawitan Bali. Pembahasan tersebut mempertegas bahwa gamelan Semar Pagulingan Saih Pitu dapat digunakan sebagai landasan dalam menggarap komposisi musik kreasi Tirtha Campuhan.

d. Sumber kajian berikutnya adalah buku yang diutlis oleh I Ketut Wiana dengan judul "Arti dan Fungsi Sarana Persembahyangan” yang mebahas tentang tirtha. Penjelasan dalam buku ini medeskripsikan bahwa kata tirtha sesungguhnya berasal dari bahasa Sansekerta, menyebutkan bahwa arti tirtha adalah toya atau air suci. Dalam beberapa kamus, arti kata tirtha berbeda-beda, namun demikian maksud dari arti kata tirtha tersebut memiliki arti dan makna yang sama.

\section{Bentuk dan Struktur Garapan}

Struktur garapan komposisi Tirtha Campuhan terdiri dari lima bagian yaitu bagian pertama pangawit, bagian kedua gagenderan, pada bagian ketiga pangawak, bagian keempat pangecet, dan pada bagian terakhir penyuud. Pada bagian pangawit, terdapat permainan kekenyongan yang diawali dengan instrumen jegog yang disambung dengan pemade. Dalam pangawit ini memakai tiga patet yang berbeda yaitu sundaren alit, selisir, dan tembung. Selain memakai tiga patet yang berbeda, terdapat pengrangrang, setelah pengrangrang terdapat permainan ritme yang halus yang menggambarkan suasana aliran air sungai mati (tukad mati) yang berada di sebelah barat, dan ditambahkan vokal berupa gerong. Dalam hal lain permaian jublag dan jegog memiliki porsi yang sama.

Pada transisi menuju bagian berikutnya dari bagian pangawit, tempo permainan instrumen gangsa lebih cepat dari tempo permainan jublag. Melodi yang sama dipakai dalam bagian kedua dengan memakai patet sundaren alit, terdapat teknik permainan kotekan yang dipadukan dengan tempo yang lebih enerjik dari bagian sebelumnya. Pada bagian gagenderan memiliki dua kali pengulangan, transisi selanjutnya jatuh pada pukulan kemong. Transisi berikutnya terdapat dua melodi, pada transisi pertama memakai semi teknik kakebyaran dengan menggunakan patet selisir. Dalam transisi bagian pertama ini terdapat pengulangan dua kali,

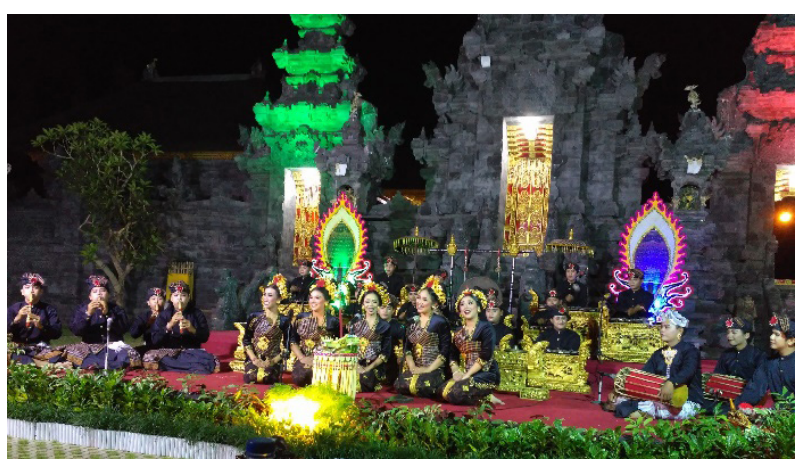

Gambar 4. Pertunjukan komposisi Tirtha Campuhan. (Sumber: Paristha, 2018) 
perubahannya terdapat pada pukulan kemong melodi, tempo dan patet yang dipakai berubah menjadi patet baro. Pada Transisi bagian kedua terdapat dua melodi yang berbeda dan terdapat unsur kekenyongan pada kotekan gangsa. Dalam hal ini dari bagian pangawit, hingga transisi ini menggambarkan bertemunya tiga aliran sungai yang akan bercampur.

Bagian ke tiga (pangawak) dalam garapan Tirtha Campuhan memakai tiga patutan yang dicampur menjadi satu kesatuan yang harmonis. Tiga patet yang awali dengan patet baro, tembung, dan selisir yang di padukan dengan kidung Sang Diah dengan melodi yang berjalan linier (berjalan lurus atau tidak ada pengulangan) pada setiap patet. Sesuai dengan konsep pencampuran dua air sungai dengan air laut yang menjadi satu dalam pusaran air yang menyerupai sumur, dalam bagian ini setelah bercampurnya tiga patet (baro, tembung, dan selisir) patet lebeng terdapat pada akhir dalam bagian ketiga. Transisi dari bagian ketiga dengan bagian berikutnya dari patet lebeng menjadi patet baro. Bagian keempat (pangecet) dalam garapan ini merupakan hasil dari pencampuran tiga patet (baro, selisir, tembung) yang di ulang sebanyak dua kali. Dalam bagian pangecet mengambarkan suasana campuran air yang sudah menjadi tirtha. Pada bagian akhir dari garapan Tirtha Campuhan menggunakan sepenggal melodi dari bagian sebelumnya dengan mendapatkan tempo lambat serta memakai patet baro. Sepenggal melodi tersebut di tambahkan dengan vokal (gerong) yang menggambarkan bahwa campuran aliran air sungai yang sudah menjadi tirtha akan di reaslisasikan kepada masyarakat sebagai tirtha penglukatan sudamala (tirtha campuhan).

\section{Wujud Garapan dan Analisis Musikal}

Komposisi tabuh kreasi Tirtha Campuhan memiliki konsep pencampuran aliran air sungai yang diaplikasikasikan dengan mencampur beberapa patet menjadi satu. Selain mencampurkan beberapa patet yang menjadi satu, unsur-unsur musik tetap digunakan dalam komposisi ini seperti, melodi, ritme, dinamika, tempo, dan harmoni. Pengolahan dari beberapa unsur musik tersebut hingga menjadi sebuah karya seni dijabarkan antara sebagai berikut:

a. Melodi merupakan jalinan nada yang diramu sedemikian rupa hingga menjadi sebuah gending. Melodi merupakan unsur penting dalam musik (Suardi, 2018). Dalam komposisi tabuh kreasi Tirtha Campuhan jalinan melodi pada setiap patet yang digunakan berbeda. Pada patet baro permainan melodi yang digunakan menggambarkan pada aliran air sungai dari barat dalam kontek niskala menggambarkan pemargin Ida Ratu Niang Sakti yang terkesan manis, dan lembut. Melodi pada patet tembung yang menggambarkan pemargin dari Ida Ratu Gde Dalem Ped yang terkesan Agung, dari arah aliran sungai dari timur. Aliran Air luat dari selatan yang menggambarkan pemargin Ida Betara Lingsir mengolah melodi dengan menggunakan patutan selisir, yang terkesan halus, dan bijaksana.

b. Irama atau ritme dalam komposisi tabuh kreasi Tirtha Campuhan memiliki irama yang sesuai dengan konsep dan struktur. Irama yang terdapat pada struktur bagian pertama, ketiga, dan kelima terdapat irama yang pelan, dan halus. Pada bagian kedua dan keempat, irama lebih lincah, serta diramu dengan alunan melodi sehingga menjadi satu kesatuan yang utuh.

c. Dinamika adalah perubahan-perubahan suasana yang dihasilkan melalui keras lirihnya suatu lagu (Suweca, 2009). Komposisi musik karawitan bisa dikatakan bagus apabila dinamika lembut dan kerasnya dalam bermain gamelan tersebut rapi atau tersusun, karena jika memainkan gamelan Bali tidak memai unsur dinamika maka penyajian dari musik tersebut terkesan kurang bagus. Dalam hal ini dinamika merupakan hal penting dalam garapan kreasi Tirtha Campuhan agar karya tabuh kreasi ini memiliki kesan yang baik untuk dinikmati.

d. Tempo adalah kecepatan ketukan yang ada dalam sebuah lagu (Rachman \& Lestari, 2012). Tempo menunjukan lambat, sedang, cepat, dan sangat cepat dalam sebuah karya seni karawitan. Tempo lambat, sedang, dan cepat bisa dimainkan sesuai dengan konsep, ritme, dan melodi. Pada garapan komposisi tabuh kreasi Tirtha 
Campuhan memiliki tempo lambat, sedang, dan cepat. Bagian pertama dalam komposisi ini penata menggunakan tempo yang lambat, lalu tempo yang cepat dimainkan pada saat transisi dari bagian satu ke bagian kedua. Pada bagian kedua, dan keempat memainkan tempo yang pelan, sedangkan pada bagian ketiga dan kelima menggunakan tempo yang lambat serta mendapatkan tambahan vokal.

e. Keselarasan antara bagian satu hingga bagian akhir dari sebuah karya komposisi tabuh kreasi Tirtha Campuhan yang tersusun menjadi satu kesatuan yang harmonis. Harmonisasi memperkuat tentang keutuhan karya yang bisa memberikan rasa nyaman, tenang, dan damai. Harmonis dalam komposisi tabuh kreasi ini terdapat pada pencampuran patet yang digabungkan menjadi satu-kesatuan hingga memperkuat rasa keutuhan dan keindahan dalam karya.

Sebuah karya seni karawitan baik itu instrumental maupun vokal tidak bisa dilepaskan dari keindahan. Keindahan dalam menilai atau menikmati sebuah karya seni itu cendrung subjektif. Unsur keindahan dalam garapan komposisi musik kreasi Tirtha Campuhan terdapat pada permainan patet. Menggunakan konsep dengan pencampuran dua aliran sungai dan satu aliran air laut yang diaplikasikan dengan pencampuran beberapa patet dalam barungan gamelan Semar Pagulingan. Permainan patet yang dicampur hingga menjadi satu-kesatuan yang harmonis disajikan dari bagian

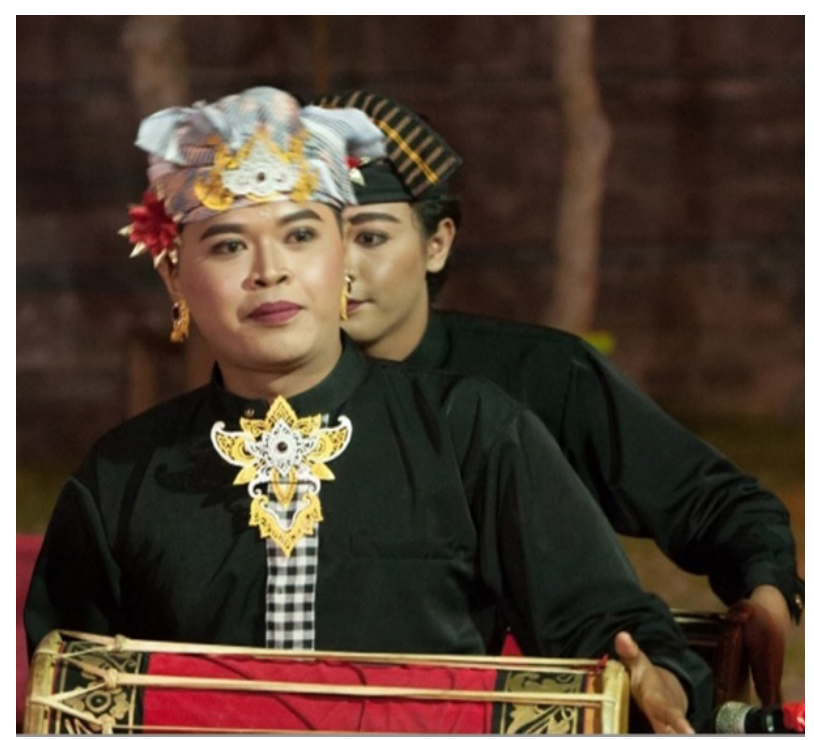

Gambar 5. Penulis dalam pementasan menabuh kendang. (Sumber: Paristha, 2018) awal hinga bagian akhir pada garapan ini. Patetpatet tersebut dijabarkan dari bagian awal, hingga munculah nilai estetis dalam bertemunya dari patet satu dengan patet yang lain.

\section{Penutup}

Pura Tirtha Campuhan menjadi landasan ide dan konsep pada garapan Tirtha Campuhan. Mendapatkan ide dari fenomena yang berada tepat di area Pura serta menggunakan konsep pada pencampuran dua aliran air sungai dengan satu aliran air laut hingga terbentuk suasana air yang menyerupai sumur. Pencampuran dua air sungai dengan satu air laut ini memiliki konteks niskala, jika pada aliran sungai dari utara pemargin Ratu Niang, pada aliran sungai dari timur pemargin Ratu Gede Dalem Ped, pada aliran air laut selatan pemargin Batare Lingsir, dan pada suasana air yang menyerupai sumur terdapat linggih Ida Tri Sakti. Pencampuran tersebut diaplikasikan dengan pencampuran beberapa patet hingga menjadi satukesatuan yang harmoni.

Tirtha Campuhan merupakan komposisi garap musik kreasi dengan menggunakan barungan gamelan Semar Pagulingan. Pada garapan ini masih berpegangan dengan pola-pola tradisi, pengembangannya terdapat pada pencampuran patet, memainkan ngempyung (yang memukul secara bersamaan dengan berjarak dua nada), dengan memainkan ubit-ubitan yang tidak sesuai dengan tempo (pada transisi dari bagian satu kebagian berikutnya), dan pada permainan unsur-unsur musikal.

Garapan komposisi musik Kreasi Tirtha Campuhan disajikan dengan konser/ karawitan mandiri dengan durasi 11.30 di jaba tengah Pura Dalem Desa Adat Ungasan. Struktur dalam garapan Tirtha Campuhan terdiri dari tiga bagian dengan memiliki dua sub pada bagian pertama dan ketiga, pada bagian pertama (pengawit) penggambaran suangi mati yang berada pada arah barat, pada sub bagian pertama (gagenderan) menggambarkan akan bercampurnya dari patet satu dengan patet berikutnya. Bagian kedua (pangawak) menggambarkan tiga patet yang becampur menjadi satu-kesatuan yang harmoni, pada bagian ketiga (pangecet) menggambarkan hasil dari pencampuran 
dari dua aliran sungai dengan satu aliran air laut, dan pada sub bagian ketiga (penyuud) hasil pencampuran tersebut akan direalisasikan menjadi Tirtha Campuhan Pengelukatan Sudamala.

\section{Ucapan Terima Kasih}

Melalui tulisan ini penulis mengucapkan terima kasih pertama-tama kepada Dekan Fakultas Seni Pertunjukan beserta jajarannya, atas tersedianya fasilitas memadai dan motivasi yang diberikan. Kemudian kepada Bapak Dr. I Gede Yudarta, S. S. Kar., Msi selaku Pembimbing I dan Bapak Dr. Hendra Santosa, S. S. Kar., M. Hum. selaku Pembimbing II yang telah meluangkan waktunya dan sabar memberikan arahan untuk menyelesaikan penulisan skrip dan karya seni sehingga selesai tepat pada waktunya. Kemudian kepada Bapak I Nyoman Kariasa, SSn., MSn, selaku Ketua Jurusan Karawitan beserta jajarannya yang telah memberikan fasilitas agar ujian tugas akhir ini dapat terselenggara. Kepada Ibu Nik Suasti yang telah turut membantu membuatkan syair, kemudian kepada para pendukung yang dengan sabar dan telaten telah mewujudkan karya komposisi gamelan Semar Pagulingan ini. Akhirnya kepada orang tua yang telah memberikan motivasi yang sangat luar biasa dan dukungan baik secara moral dan material.

\section{Kepustakaan}

Agus, I. M., Antara, B., Sudirga, I. K., \& Santosa, H. (2018). Cak Ganjur : Sebuah Komposisi Musik Vokal Gabungan Cak Dan Balaganjur, 4(september), 96-104.

Bandem, I. made. (1995). No Title. In Ensiklopedi Gamelan Bali. Proyek Pembinaan Penggalian dan Pengembangan Seni Klasik/Tradisional dan Kesenian Baru Pemerintah Daerah tingkat 1 Bali.

Diaristha, P. F., Sutirtha, I. W., \& Widnyana, K. G. (2018). Tari Ipit: Dari Penyakit Kesajian Artistik. Jurnal Seni Pertunjukan, 4(1).

Djelantik, A. A. M. (1990). Pengantar Dasar Ilmu Estetika Jilid 1: Estetika Instrumental. Denpasar.

Donder, I. K. (2005). Esensi bunyi gamelan dalam prosesi ritual Hindu: perspektiffilosofis-teologis, psikologis, sosiologis, dan sains. Paramita.

Garwa, I. K. (2009). Buku Ajar Komposisi Karawitan $I V$. Denpasar: Institut Seni Indonesia.

Hawkins, A. M. (1990). Mencipta Lewat Tari (terjemahan oleh Y. Sumandiyo Hadi). Yogyakarta: Institut Seni Indonesia.

Rachman, A., \& Lestari, W. (2012). Bentuk Aransemen Musik Keroncong asli Karya Kelly Puspito dan Relevansinya Bagi Remaja Dalam Mengembangkan Musik Keroncong Asli. Catharsis, 1(2).

Rai, i W. (1998). Peranan Sruti Dalam Pepatutan Gamelan Semar Pagulingan Saih Pitu. Denpasar.

Santosa, H. (2019). Gamelan Sistem Sepuluh Nada dalam Satu Gembyang untuk Olah Kreativitas Karawitan Bali. PANTUN, 1(2).

Slamet, R. C., \& Djohan, D. (2017). Musik Batu. Resital: Jurnal Seni Pertunjukan, 18(2), 65-77.

Suaida, S., Novalinda, S., \& Erman, S. (2018). Konsep Ritual Dalam Penciptaan Karya Tari Gilo Lukah. LAGA-LAGA: Jurnal Seni Pertunjukan, 4(2), 129-139.

Suardi, R. (2018). Musik Tari Rentak Buliandi Sanggar Kamboja SMPN 1 Rengat Kabupaten Indragiri Hulu Provinsi Riau (Analisis Unsur Melodi). Virtuoso (Jurnal Pengkajian Dan Penciptaan Musik), 1(1), 1-7.

Sugiartha, I. G. A. (2008). Gamelan pegambuhan" tambang emas" karawitan Bali. Institut Seni Indonesia Denpasar.

Sugiartha, I. G. A. (2012). Kreativitas Musik Bali Garapan Baru; Perspektif Culture Studies. ISI Denpasar.

Suneko, A. (2016). Pyang Pyung: sebuah komposisi karawitan. Resital: Jurnal Seni Pertunjukan, 17(1), 60-66.

Susanti, D. (2015). Penerapan Metode Penciptaan Alma Hawkins Dalam Karya Tari Gundah Kancah. Ekspresi Seni: Jurnal Ilmu Pengetahuan Dan Karya Seni, 17(1), 41-56.

Suweca, I. W. (2009). Buku Ajar Estetika Karawitan. Denpasar: Fakultas Seni Pertunjukan Institut Seni Indonesia Denpasar.

Warsana, M. (2012). Berkarya Musik: antara Harapan dan Tantangan. Selonding, 1(1). 